\title{
Estimating direct and indirect effects of foreign direct investment on firm productivity in the presence of interactions between firms
}

\author{
Sourafel Girma \\ University of Nottingham and GEP \\ Yundan Gong \\ Aston Business School \\ Holger Görg \\ Kiel Institute for the World Economy; University of Kiel and IZA \\ Sandra Lancheros \\ University of Nottingham Ningbo China and GEP
}

\begin{abstract}
We implement a method to estimate the direct effects of foreign-ownership on foreign firms' productivity and the indirect effects (or spillovers) from the presence of foreign-owned firms on other foreign and domestic firms' productivity in a unifying framework, taking interactions between firms into account. To do so, we relax a fundamental assumption made in empirical studies examining a direct causal effect of foreign ownership on firm productivity, namely that of no interactions between firms. Based on our approach, we are able to combine direct and indirect effects of foreign ownership and calculate the total effect of foreign firms on local productivity. Our results show that all these effects vary with the level of foreign presence within a cluster, an important finding for the academic literature and policy debate on the benefits of attracting foreign owned firms.
\end{abstract}




\section{Introduction}

When considering the impact of inward foreign direct investment on host country productivity, researchers and policy makers generally think about two aspects. The first is the direct effect of foreign ownership, boiling down to the question as to whether affiliates of foreign multinationals in a host country are more productive than comparable domestic firms. The second aspect is "spillovers", i.e., whether there is any effect from the presence of foreign firms on the productivity of domestic or other foreign-owned firms. These two questions have been pursued in, for the most part, two separate literatures.

One research strand (e.g., Harris and Robinson, 2002, Girma and Görg, 2007a, Arnold and Javorcik, 2009) implements methods from microeconometric programme evaluation to estimate the direct treatment effects for firms receiving the "treatment" of being foreign compared to non-treated domestic firms (without considering "spillovers"). This literature appeals to theoretical models of multinationals, either in the tradition of the knowledge capital model as in Markusen (2001), or the more recent models of heterogeneous firms (e.g., Helpman et al., 2004), which assume that foreign owned multinationals have firm specific assets which translate into a productivity advantage. The second research strand (e.g., Aitken and Harrison, 1999, Haskel et al., 2007, Keller and Yeaple, 2009) looks at indirect effects through productivity "spillovers" (while largely neglecting direct treatment effects). The theoretical intuition is that domestic firms can learn from the presence of foreign multinationals in their vicinity, e.g., because workers move from a foreign firm to a domestic competitor (e.g., Fosfuri et al., 2001).

Examining direct effects and spillovers in isolation leads to potentially biased estimates and policy conclusions, however. When evaluating the direct treatment effect of foreign ownership, the econometric approaches assume that the productivity of the control group is 
independent of foreign ownership - an assumption in contrast with the idea of spillovers. ${ }^{1}$ In the "spillovers literature", identification of the effects of foreign ownership at the industry level on domestic firm productivity is problematic because of endogeneity concerns - there are industry or region specific shocks that positively affect domestic firms' productivity and raise the attractiveness of the location for foreign multinationals.

In this paper, we bring the two strands of literature together and propose and implement a unified framework to estimate direct and indirect effects from foreign ownership on firm level productivity which allows for interaction between foreign and domestic, and foreign and foreign firms. Our approach, detailed in the following sections, allows us to estimate consistently a number of different treatment effects. In particular, we can distinguish the direct effect of foreign ownership on the treated firms and two types of indirect effects of the treatment, namely the indirect effects on treated and non-treated firms. These indirect effects, thus, capture externalities or learning effects from foreign firms on other foreign (i.e., treated) or domestic firms (i.e., non-treated). Furthermore, combining the direct and indirect effects we can calculate a total effect of foreign firms on local productivity.

Distinguishing these effects is not only of academic merit but also highly policy relevant, as it allows us to provide much richer and sharper insights on the nexus between foreign ownership, proximity to foreign-owned firms, and firm productivity. Hence, the approach suggested here provides a very useful tool for policymakers to understand better the benefits of encouraging foreign direct investment

We implement our econometric framework using firm level data for Chinese manufacturing. Following, Hudgens and Halloran (2008) our approach to take into account the role of interactions among firms when evaluating the effects of foreign ownership on firms' productivity is to use the proportion of foreign firms within well-defined clusters at the

\footnotetext{
${ }^{1}$ This is known as the Stable Unit Treatment Value Assumption (SUTVA), which states that an individual outcome does not depend on the treatment status of others.
} 
industry-region level. Thus, the potential outcomes depend not only on the firm's treatment status, but also on the fraction of foreign firms in a particular cluster.

Our empirical results show that the direct effect of the treatment on the treated firms is not homogenous across industry-region clusters, but rather differs strongly across such clusters. In particular, we find that the direct effect of foreign-ownership on the treated (i.e. foreign-owned) firms is positive and increases strongly with the overall level of foreignowned firms in a cluster. This suggests that the standard approach of estimating direct treatment effects, which neglects interactions between firms, fails to uncover potentially important heterogeneity in the effect across clusters.

On the other hand, we find a consistently negative indirect effect of foreign-ownership on non-treated firms, indicating negative "spillovers" from foreign presence on domestic firms. Also, in contrast to much of the literature on spillovers cited above, our approach shows that the strength of this negative spillover is not constant but differs significantly with the level of foreign ownership in a cluster. Spillovers are more negative with increasing presence of foreign firms up to a threshold of around 40 percent foreign-owned firms, after which they become less negative.

In terms of the indirect impact of foreign ownership on the treated (i.e. the spillovers from the presence of foreign firms on other foreign firms in the same cluster), we also find a negative effect up to a level of 40 percent foreign-owned firms in a cluster. However, after reaching this threshold these effects turn positive. This has important implications for arguments favouring the agglomeration of foreign-owned firms in a cluster, as this shows that the benefits from such agglomerations might only become positive once a certain threshold is reached.

The remainder of the paper is structured as follows. Section 2 presents the theoretical motivation of the paper. Section 3 discusses our identification strategy and introduces the different types of effects we aim to estimate. Section 4 presents the data set that we use to 
illustrate our arguments, while Section 5 gives a detailed explanation of the estimation of the average potential outcomes, key ingredients in the identification of causal effects. Section 6 discusses the main findings of the paper, and Section 7 concludes.

\section{Theoretical motivation}

In this section we sketch out a simple theoretical framework in order to motivate the empirical analysis. The model is closely related to Guadalupe et al. (2012) (GKT), who look at the impact of foreign investment on firms' innovation activities in a model of firm heterogeneity. They, however, only look at a direct causal effect of foreign acquisition, implicitly assuming no spillover effects. To capture such spillovers, our theoretical sketch essentially re-interprets their model for a case in which firms' productivity enhancing activities also depend on the presence of other foreign firms in a cluster and the capacity of foreign and domestic firms to absorb spillovers from FDI.

As in GKT we work with a model with heterogeneous firms in a monopolistic competition setting and a CES demand function. Firm $i$ has an initial productivity level of $\varphi_{i}$ and it can make a productivity enhancing investment, $\gamma_{i}$. In GKT this investment is considered to be innovation. We take a broader view and consider this to be any activity that is productivity-increasing at the firm level, and that will lead to a measurable increase in productivity as a result of firm level foreign investment.

Firm's $i$ profits are given by

$$
\pi_{\mathrm{i}}=\mathrm{B}_{i} \tau_{\mathrm{i}} \phi_{\mathrm{i}}
$$

where $\mathrm{B}_{i}=\mathrm{A}_{i}\left(\frac{1-\rho}{\rho}\right) \rho^{\sigma}$ with $A$ being market size and $\rho$ defining the elasticity of substitution between varieties $\sigma=1 /(1-\rho) .^{2}$ For ease of exposition we define $\tau_{\mathrm{i}}=\left(\gamma_{i}\right)^{\sigma-1}$ and $\phi_{\mathrm{i}}=$

\footnotetext{
${ }^{2}$ Guadalupe et al. (2012) allow the parameter $A$ to vary across foreign and domestic firms. Their idea is that foreign firms may have access to larger markets than domestic firms. We simplify this model and abstract from
} 
$\varphi_{\mathrm{i}}{ }^{\sigma-1}$ which are transformed measures of productivity-enhancing investments and initial productivity, respectively. Firms must engage in costly investments in order to increase their productivity level. As in GKT we assume that the cost of such investments $\left(C_{i}\right)$ include a fixed and a variable component, as follows:

$$
C_{i}=a_{i}+\frac{b_{i}}{\alpha_{i} N_{r}} f\left(\tau_{i}\right)
$$

with $f$ denoting a general positive function of $\tau_{i}$ without specific assumptions about its functional form.

In GKT, foreign ownership impacts innovation only by affecting the parameters $a_{i}$ and $b_{i}$. We follow their approach and assume that these parameters are positive and lower for foreign $(F)$ than for domestic firms $(D): 0 \leq b_{F}<b_{D}$ and $0 \leq a_{F}<a_{D}$. This reflects the foreign multinational's access to better technology, or lower costs of financing, which imply that the firm has lower costs for implementing productivity enhancing investments. We interpret this as the direct effect of foreign ownership on firms' productivity, which we attempt to identify in our empirical analysis.

To capture the indirect effects from other foreign firms, we extend GKT by allowing the variable cost of productivity enhancing investment also to depend on: i) the number of foreign firms in a cluster $\left(N_{r}\right)$, and ii) a firm specific constant, capturing its capacity to absorb spillovers from foreign firms $\left(\alpha_{i}\right)$. The assumption that the cost of productivity enhancing technologies depends on the number of foreign firms $\left(N_{r}\right)$ captures the notion of spillovers. These are generally expected to be positive due to learning effects. While we do not model the exact underlying mechanism (which we also cannot measure in our data), one reasonable interpretation for such positive effects is worker movements. As discussed by Fosfuri et al. (2001), domestic workers may be hired by foreign firms (which possess superior technology)

this market size effect in order to be able to focus on the effect we find more relevant, namely, the effects of foreign ownership on the cost of productivity enhancing investments. 
and then trained to be able to use the up-to-date technology. ${ }^{3}$ After a period of training, they may then either remain in the foreign-owned firm or move to a domestic competitor. In the latter case, they take with them some knowledge about technology, which then makes it easier for the domestic firm to implement this new technology. A domestic firm without a foreigntrained worker is not able to do so. Hence, the costs of improving technology are, in this case, lower for the domestic firm with foreign-trained worker than for the domestic firm without. We assume that the chance of being able to employ such a foreign-trained worker is increasing in the number of foreign-owned firms. ${ }^{4}$

However, the empirical literature shows that spillovers may also be negative, see for example Aitken and Harrison (1999). This is generally attributed to competition effects. Multinationals have lower marginal costs due to some firm-specific advantage, which allows them to attract demand away from domestic firms, thus forcing the domestic firms to reduce production and move up their (given) average cost curve. This leads to lower productivity. Whether the spillover effect is positive or negative is, hence, an empirical issue.

The second innovation in our model is the inclusion of the firm specific term, $\alpha_{i}$, which measures the strength with which spillovers affect firm $i$. This captures the idea that spillover effects may not be uniform across firms but may differ depending on some firm specific characteristic. Görg and Greenaway (2004), for example, argue that whether a firm benefits from spillovers may depend on its relative backwardness and its capacity for assimilating knowledge. In particular, foreign firms with access to superior technology are likely to benefit more from the presence of other foreign firms in the cluster. To capture the notion of heterogeneity in the spillover effects we allow the parameter $\alpha_{i}$ to be different for domestic and foreign firms. In particular we assume $\alpha_{F}>\alpha_{D}$, indicating the superiority of

\footnotetext{
${ }^{3}$ Görg and Strobl (2005) provide empirical evidence from firm level data for Ghana.

${ }^{4}$ There may also be other channels for spillovers from multinationals to domestic firms, such as learning externalities or vertical linkages. See Keller (2010) for a discussion.
} 
foreign firms to absorb positive foreign spillovers. We can identify these two different indirect effects on foreign and domestic firms in our empirical work.

Given the operating profits and the cost of improvements in productivity, the value of a firm $i$ is given by

$$
V_{i}=\mathrm{B}_{i} \tau_{\mathrm{i}} \phi_{\mathrm{i}}-a_{i}-\frac{b_{i}}{\alpha_{i} N_{r}} f\left(\tau_{i}\right)
$$

To determine the level of investment in productivity enhancing technology that maximizes the value of the firm we set the first derivative $\left(d V_{i} / d \tau_{i}\right)$ equal to zero and obtain

$$
\alpha_{i} N_{r} \mathrm{~B}_{i} \phi_{\mathrm{i}}=b_{i} f^{\prime}\left(\tau_{i}^{*}\right)
$$

Equation 4 implies that productivity enhancing investment is higher (i) the lower is $b_{i}$, (ii) the higher is the spillover effect from the number of foreign firms $\left(\alpha_{i} N_{r}\right)$ and (iii) the higher is initial productivity $\phi_{\mathrm{i}}$. In other words, as in GKT, there is a direct effect of foreign ownership on productivity enhancing investment as foreign firms have lower $b_{i}$. Moreover, expanding on GKT, there is also an indirect effect through the number of foreign firms in the cluster $\left(N_{r}\right)$ and this indirect effect is different for foreign and domestic firms (which have different $\alpha_{i}$ ). Finally, the First Order Condition (FOC) given by equation 4 also suggests that initial productivity plays a role for firms' investments in productivity enhancing technology.

An important insight from equation (4) is that the FOC does not separately identify $\alpha_{i} N_{r}$ or $b_{i}$ but only the ratio $\alpha_{i} N_{r} / b_{i}$. Not taking into account the impact of $\alpha_{i} N_{r}$ in an empirical estimation of the direct effect of foreign ownership (due to $b_{i}$ ) would imply that the estimated direct effect might be biased. Depending on the specific assumption about the expected effect of $\alpha_{\mathrm{i}} \mathrm{N}_{\mathrm{r}}$ it would be either over- or underestimated. In our empirical framework, we can 
separate these effects and obtain an unbiased estimate of the direct causal effect due to $b_{i}$ and also estimate the indirect effects of foreign ownership on foreign and domestic firms.

We can also say something about the acquisition decision, which is unlikely to be random. In order to see whether an acquisition is profitable, we can compare the value of a firm (given in equation 3) under foreign and domestic ownership. Specifically, given the different characteristics of firms according to their ownership structure, the difference in value, at the optimal level of investment in new technology $\tau_{i}^{*}$, between a foreign and domestic firm is given by

$$
V_{i}^{F *}-V_{i}^{D *}=\left(\tau_{i}^{F *}-\tau_{i}^{D *}\right) \mathrm{B}_{i} \phi_{\mathrm{i}}-\left(a_{F}-a_{D}\right)-\left(\frac{b_{F}}{\alpha_{F} N_{r}} f\left(\tau_{i}^{F *}\right)-\frac{b_{D}}{\alpha_{D} N_{r}} f\left(\tau_{i}^{D *}\right)\right)
$$

Differentiating this with respect to $\phi_{\mathrm{i}}$ yields a positive expression, indicating that the difference in value is increasing in initial productivity.

$$
d\left(V_{i}^{F *}-V_{i}^{D *}\right) / d \phi_{\mathrm{i}}=\left(\tau_{i}^{F *}-\tau_{i}^{D *}\right) \mathrm{B}_{i}
$$

Hence, the value enhancing benefits from foreign acquisitions are more pronounced for firms with high initial productivity, or, in other words, foreign acquired targets in the host country are likely to be more productive prior to acquisition. This result arises from the assumption that any investment in productivity is more valuable under foreign control. For our empirical implementation this implies that we need to control for initial productivity when attempting to identify the direct effect of foreign ownership, which we do in a propensity score framework.

In our set up we can also look at how the acquisition incentives change with the number of existing foreign firms in the cluster $\left(N_{r}\right)$. The sign of the partial derivative 


$$
d\left(V_{i}^{F *}-V_{i}^{D *}\right) / d N_{r}=\frac{b_{F}}{\alpha_{F} N_{r}^{2}} f\left(\tau_{i}^{F *}\right)+\frac{b_{D}}{\alpha_{D} N_{r}^{2}} f\left(\tau_{i}^{D *}\right)
$$

depends on the sign of the parameters $\alpha_{F}$ and $\alpha_{D}$. For example, in the case where $\alpha_{F}>\alpha_{D}>$ 0 (that is, assuming that foreign firms have relatively higher absorptive capacity) expression 7 is unambiguously positive, indicating that the incremental value of the firm under foreign ownership is increasing in the number of foreign firms in the cluster. Thus, acquisition is more likely in clusters with a high presence of foreign firms. We control for this also in our empirical estimation.

To sum up, our theoretical discussion provides a basis for expecting a positive direct effect of foreign ownership on productivity enhancing investments in a firm. There are also potentially different indirect effects of foreign ownership on foreign and domestic firms, and these need to be taken into account in order to obtain an unbiased estimate of the direct effect. Furthermore, the acquisition decision is not random, but may be related to firms' initial productivity and the number of foreign firms in a cluster. We now turn to the empirical analysis.

\section{Identification strategy}

The estimation of direct and indirect effects of foreign ownership on productivity is rendered difficult because of an important assumption in the commonly used microeconometric approaches for estimating direct effects - the Stable Unit Treatment Value Assumption (SUTVA). This assumption essentially states that an individual outcome does not depend on the treatment status of others. Or, in other words, there are no indirect effects (or spillovers) from all treated individuals on the outcome for an individual. Translated into 
the specifics of the FDI and productivity debate, the assumption implies that the average productivity of a firm (foreign or domestic) is not influenced by the presence of other treated (i.e., foreign-owned) firms. This assumption is, thus, in direct contrast to the notion of "productivity spillovers". This implies that it is likely that SUTVA is violated in studies looking at productivity differences between foreign and domestic firms using standard microeconometric evaluation techniques.

Our approach to estimating consistently direct and indirect effects of foreign ownership is based on recent work in the statistical and econometric literature that has sought to relax SUTVA. ${ }^{5}$ According to this literature, treatment externalities (or spillovers) occur when an individual's potential outcome is affected by other individuals' treatment status within a group. The approach we take, following Hudgens and Halloran (2008), is to use the proportion of treated firms within a group as a measure of interaction between individual firms. ${ }^{6}$ The potential outcomes are thus expressed as a function of the firm's treatment status and the fraction of foreign firms in a particular group or cluster.

Suppose we have $r=1 \ldots R$ sufficiently heterogeneous economic clusters, which for the purpose of this application we define in terms of broad industry groups and geographical areas as industry-region clusters. A key identifying assumption is the so-called partial interference assumption where SUTVA holds across clusters but not within clusters. In other words, we only allow interactions between firms in the same industry and geographic area. We use this definition of clusters as it is in line with the finding in much of the empirical

\footnotetext{
${ }^{5}$ Seminal theoretical papers on "causal inference with interactions" include Sobel (2006); Rosenbaum (2007); Hudgens and Halloran (2008) and Manski (2013). Building on these works Ferracci et al. (2014) provide a comprehensive study of the impacts of training programmes on unemployment duration in the presence of interactions in the local labour markets. Angelucci and de Giorgi (2009) employ village-level randomisation to assess the indirect impact of cash transfer program in Mexico.

${ }^{6}$ The most general (extreme) case of interactions are "unrestricted interactions" between all individuals within a group, in which case potential outcomes are not only functions of the individual's treatment status, but also of all possible combinations of treatments. With unrestricted interactions, calculating the number of potential outcomes might become impracticable if the population size is large. Hence, in order to be able to implement this approach, we follow Hudgens and Halloran (2008) and place some restrictions on the possible interactions.
} 
work that "spillovers" from FDI appear strongest if they happen in the same broad industry and region (e.g., Girma and Wakelin, 2007, $\mathrm{Xu}$ and Sheng, 2012). ${ }^{7}$ Also, this definition (instead of using clusters based solely on, say, industry classification, or regions) provides us with a sufficiently large number of clusters.

For ease of exposition we assume that there are $i=1 \ldots N$ firms in each cluster and $N_{r}$ of these receive the treatment, i.e., in our case, have some amount of foreign ownership. Hence, the proportion of treated firms is $p_{r}=\frac{N_{r}}{N}, r=1, \ldots, R$. Restricting ourselves to a binary treatment variable $\left(d_{i r}=1\right.$ if firm $i$ in cluster $r$ has foreign ownership and $d_{i r}=0$ if not), we have $p_{r}=\frac{N_{r}}{N}=\frac{\sum_{i}^{N} d_{i r}}{N}$

Letting $y$ be the outcome variable (i.e. firm productivity) there are two potential outcomes, $y^{0}$ and $y^{1}$, corresponding to the two treatment states. Only one of those can be observed for any one firm. If SUTVA holds within clusters, an individual's potential outcomes are only a function of its own treatment status:

$$
E\left(y_{i r} \mid d_{i r}\right) \equiv y_{i r}^{d}=y_{i r}^{d}\left(d_{i r}\right) ; d=0,1
$$

If SUTVA does not hold, one can think of the extreme case of unrestricted interactions between all individuals within a cluster, in which case potential outcomes are not only functions of the individual's treatment status, but also of all $2^{N}$ combinations of treatments, say $d_{i r}^{-}: y_{i r}^{d}=y_{i r}^{d}\left(d_{i r}, d_{i r}^{-}\right) ; d=0,1$. Following Hudgens and Halloran (2008), it makes practical sense to think in terms of the distribution of the treatment variable within a cluster, rather than of all possible treatment combinations.

\footnotetext{
${ }^{7}$ Note that we do not see this definition as excluding spillovers from vertical linkages, as highlighted by Javorcik (2004), as our industrial classification (see Appendix A) is sufficiently broad to also include vertical links. Moreover, our approach may be seen as offering a new alternative way of estimating intra-cluster spillovers.
} 
A natural starting point is to consider the proportion of treated firms in the cluster, $p_{r}=\frac{N_{r}}{N}$. The potential outcomes under the two treatment states can then be expressed as a function of the individual's treatment status and $p_{r}$ :

$$
y_{i r}^{d} \equiv y_{i r}^{d}\left(p_{r}\right) ; d=0,1 \text { and } p_{r} \in[0,1]
$$

Now we define the average (across independent clusters) potential outcomes corresponding to the two treatment states as a function of the proportion of treated individuals (i.e. share of firms with foreign ownership in a cluster) as follows:

$$
\bar{y}_{p}^{d}=E_{r}\left[\bar{y}_{r}^{d}\left(p_{r}\right)\right] ; d=0,1 \text { and } p_{r} \in[0,1]
$$

If $\frac{\partial \bar{y}_{p}^{d}}{\partial p} \neq 0$ for any $\boldsymbol{d}$, then SUTVA would not be supported by the data. This is intuitive as an individual's potential outcomes should be independent of other individuals' treatment status for the assumption of no treatment externalities to hold in the data.

Once the average potential outcomes $\bar{y}_{p}^{d}$ are constructed for $d=0,1$ and all possible relevant values $p_{r} \in[0,1]$, various treatment effect parameters can be defined and estimated. Like all causal effect estimators, these are defined as differences between two average potential outcomes. As discussed by Hudgens and Halloran (2008), four causal treatment effect parameters may be of particular interest:

i. The direct causal effect of the treatment (Equation 11), which compares average potential outcomes for a firm with foreign ownership with the potential outcome for that firm without FDI, keeping the cluster-specific treatment level constant at $\boldsymbol{p}$ (i.e. keeping possible interactions fixed).

$$
\bar{\gamma}_{p p}^{10}=\bar{y}_{p}^{1}-\bar{y}_{p}^{0}
$$


ii. The indirect effect on the non-treated (Equation 12), which in this literature is generally referred to as an FDI "spillover" on domestic firms. This estimator is defined as the change in the potential outcome of non-foreign-owned firms resulting from increasing the clusterspecific proportion of foreign firms from 0 to $\boldsymbol{p}$.

$$
\bar{\gamma}_{p 0}^{00}=\bar{y}_{p}^{0}-\bar{y}_{0}^{0}
$$

iii. The total treatment effect (Equation 13), which captures the change in the potential outcome of foreign firms when the proportion of foreign firms in the cluster is $\boldsymbol{p}>0$ compared to the no-treatment outcome that would occur if $\boldsymbol{p}=0$ (i.e., no foreign firms in the cluster).

$$
\bar{\gamma}_{p 0}^{10}=\bar{y}_{p}^{1}-\bar{y}_{0}^{0}
$$

As shown by Hudgens and Halloran (2008), the total treatment effect can be decomposed into direct and indirect effects, that is $\bar{\gamma}_{p 0}^{10}=\bar{\gamma}_{p p}^{10}+\bar{\gamma}_{p 0}^{00}$.

iv. The marginal treatment effect on the treated - or indirect effect on the treated- (Equation 14), which measures the marginal change in the potential outcome for foreign-owned firms when the proportion of foreign firms goes from 0 to $\boldsymbol{p}$ (Hudgens and Halloran (2008). In other words, this captures a "spillover" of FDI activity on foreign-owned firms themselves.

$$
\bar{\gamma}_{p 0}^{11}=\bar{y}_{p}^{1}-\bar{y}_{0}^{1}
$$

Next we turn to the discussion of the data used in our empirical analysis. ${ }^{8}$

\section{Data description}

\footnotetext{
${ }^{8}$ It is worth noting that the benchmark treatment level in equations (11)-(14) need not be 0: comparisons can be made between any two treatment levels. For example, if interest lies in estimating the indirect effects of increasing the proportion of FDI firms from $20 \%$ to $30 \%$ we would compute $\bar{\gamma}_{0.30,0.20}^{00}=\bar{y}_{0.30}^{0}-\bar{y}_{0.20}^{0}$.
} 
We implement the empirical analysis using firm level data from the Chinese manufacturing industry. The dataset is based on the Annual Reports of Industrial Enterprise Statistics, compiled by the China National Bureau of Statistics. The dataset covers all firms in China with an annual turnover of more than 5 million Renminbi (about $\$ 800,000$ ). These companies account for an estimated 85-90 percent of total output in most industries. For the purpose of this analysis, we have more than 147,000 firms over the period 2004-2006. Our "treatment" is defined as a firm having foreign investment in $2005 .{ }^{9}$

Table 1 gives some summary statistics of variables of interest by foreign ownership status. These include pre-treatment (i.e. in 2004) firm characteristics and the pre and post treatment (2004 and 2006) of the outcome variable, which is the log of labour productivity defined as value added per worker. ${ }^{10}$ As one might expect, there are substantial differences between domestic and foreign firms vindicating the adoption of a treatment effects evaluation framework. The raw data suggest that on average foreign and domestic firms recorded approximately a $30 \%$ and $15 \%$ cumulative growth in productivity respectively between 2004 and 2006. Using a relatively naïve difference-in-differences estimator, one would have concluded that the causal effect of foreign ownership is to the tune of $15 \%$.

As discussed in the previous section, our identification strategy invokes the partial interference assumption where firm interaction is freely allowed within well-defined clusters. In this paper we classify firms into clusters based on 11 geographic areas and 13 broadly defined industries. $^{11}$ This gives us 127 clusters, half of which comprise of at least 768

\footnotetext{
${ }^{9}$ A firm is deemed to have foreign ownership if foreign investment accounts for at least $10 \%$ of firms' paid-up capital.

${ }^{10}$ Value added per worker is deflated by the consumer price index. Since our main objective is to suggest a framework for estimating the direct and indirect effects of FDI in a unified way, we want to abstract from the various well-documented econometric issues plaguing the estimation of TFP, and concentrate rather on value added per worker (which in any case is found to be highly correlated with TFP in most countries' micro data). However, below we also provide a robustness check and report results based on TFP estimated following Levinsohn and Petrin (2003).

${ }^{11}$ See Appendix A for a list of geographic areas and industries.
} 
firms. ${ }^{12}$ Table 2 reports some summary statistics of cluster level variables. The average proportion of firms with foreign ownership in a cluster is about 21 percent. It is also apparent from the various measures of dispersion given in Table 2 that clusters are quite heterogeneous in terms of average characteristics. Table 3 reports the number of foreign firms and proportion of foreign (treated) firms by cluster. As can be seen, there is substantial heterogeneity across clusters. Furthermore, Table 4 shows that the proportion of foreign firms in a cluster exhibits significant correlation with average cluster-specific characteristics.

The next section discusses the econometric implementation of the approach outlined in Section 3, which proceeds in two steps.

\section{Empirical implementation}

\subsection{Estimation of potential outcomes}

In the first step we focus on the estimation of potential or counterfactual outcomes (equation 10) as this is a key ingredient for estimating treatment effect parameters (equations 11 - 14) which are defined as differences between average potential outcomes. Accordingly, for each of the 127 clusters, we estimate the average potential outcomes $\bar{y}_{r}^{1}$ and $\bar{y}_{r}^{0}$ under FDI and no FDI scenarios respectively [see equation (10)], where $y$ denotes the outcome variable, labour productivity.

In order to deal with selection and unobserved heterogeneity in this estimation we apply the conditional independence assumption (CIA) as in the propensity-score matching literature (Rubin, 1974). This involves estimating the propensity of a firm receiving treatment (i.e., being foreign owned) by conditioning the treatment dummy variable (which is equal to one if a firm has foreign ownership and zero else) on a vector of the following pre-treatment firm characteristics: wages (level and growth), productivity (level and growth), size (log of total

\footnotetext{
${ }^{12}$ We impose the condition that at least $4 \%$ of firms in a cluster should be foreign-invested and the total number of firms should not be less than 100. For this reason we have to leave out 17 clusters from the analysis.
} 
assets), age, export intensity, and motivated by the theoretical discussion in Section 2, the number of foreign firms in the firm's region. To account for firm-level unobserved heterogeneity, we combine CIA with difference-in-differences (cf., Girma and Görg, 2007b) by considering the change in the outcome variables between post (2006) and pre-treatment (2004) periods. However, for ease of exposition, we maintain the $y$ notation for the outcome variables.

In the empirical implementation we identify the expected individual outcomes per cluster by estimating the outcome equation using inverse propensity-score weighted regression also controlling for the pre-treatment covariates (Hirano, Imbens and Ridder, 2003). ${ }^{13}$ For each cluster, this involves:

a. Generating the propensity-score $(\rho)$ of being treated via a logistic regression with $\boldsymbol{X}$ as covariates. $^{14}$

b. Estimating the following outcome equation (after imposing the common support condition) via inverse probability weighted regression, with treated firms getting weight of $1 / \rho$ and non-treated firms getting weight of $1 / 1-\rho$,

$$
y_{i r}=\alpha+\beta d_{i r}+\delta X+\text { error } ; i=1 \ldots N \text {. }
$$

c. Finally computing the cluster specific potential outcomes based on the estimated regressions as ${ }^{15}$

\footnotetext{
13 Before implementing this approach, we carry out a standard propensity score matching combined with difference in differences analysis for comparison. This standard PSM, of course, relies on SUTVA. Applying this technique we find that foreign ownership has a positive causal effect on productivity with a magnitude of around 15 percent. The PSM estimation is based on nearest neighbour matching as applied in Girma and Görg (2007b), with successful balancing tests and imposing common support. Details are not provided here to save space, but can be obtained from the authors upon request.

${ }^{14}$ See Appendix B for a summary of the estimated coefficients from the cluster-specific logit model. Covariate balancing tests, which consist of testing for difference (at $10 \%$ level or lower) between the average values of the covariates in treatment and control groups, conditional on the propensity score, are given in the last column of the table in Appendix B.
} 


$$
\bar{y}_{r}^{1}=\frac{1}{N} \sum_{i=1}^{N} \hat{\alpha}+\hat{\beta}+\hat{\delta} X \text { and } \bar{y}_{r}^{0}=\frac{1}{N} \sum_{i=1}^{N} \hat{\alpha}+\hat{\delta} \mathrm{X}
$$

\subsection{Calculating treatment effects}

In the second step, we use the estimated cluster-specific potential outcomes to estimate the direct and indirect effects of FDI on firms' productivity in the presence of interaction between firms. To this end, we use the proportion of foreign firms in the cluster as a measure of firms' interactions. Hence, we treat the cluster level average potential outcomes under foreign ownership and no foreign ownership, $\bar{y}_{r}^{1}$ and $\bar{y}_{r}^{0}$, (estimated in the first step) as our "outcome" variables and the proportion of foreign firms in each cluster as our (continuous) "treatment" variable. In other words, once the average potential outcomes $\bar{y}_{p}^{d}$ are constructed for $d=0,1$ and all relevant values $p$ the various treatment effect parameters can be estimated. We do this using a causal inference approach for continuous treatments. This step involves working with cluster level variables and conditioning on the general propensity score for the proportion of foreign firms in a cluster (see Appendix C for details).

\subsection{Does SUTVA hold?}

Before commencing with this estimation we briefly consider the validity of SUTVA in our data. We do so by firstly checking whether there is a correlation between these clusterspecific ATEs estimated using equations 15 and 16 and the observed proportion of foreign owned firms in the cluster. Figure 1 presents a scatter plot as well as a regression line from a nonparametric regression of the ATE on the proportion of treated firms in the cluster. Taken at face value, this indicates fairly heterogeneous behaviour across treatment clusters,

\footnotetext{
${ }^{15}$ Note that under SUTVA, the difference between these two potential outcomes $(\hat{\beta})$ would give a consistent estimator of the average treatment effect (ATE) in each cluster.
} 
suggesting that SUTVA is unlikely to be satisfied by the data (i.e., a firm's potential outcome is not independent of the treatment level per cluster).

However, as shown in Table 4, clusters also differ along a line of other characteristics. Hence, to further test the validity of SUTVA, we investigate more formally the existence of a causal link between potential outcomes and the proportion of foreign firms in a cluster using a generalised propensity score (GPS) technique. Our results, presented in Figure C1 (appendix C), show that the potential outcomes (for treated and untreated firms) vary systematically with the treatment level in the cluster, suggesting that SUTVA does not hold.

Hence, the standard PSM approach masks substantial cross cluster heterogeneity, as is obvious from Figures 1 and $\mathrm{C} 1$. Our novel approach, as explained in the previous sections, arguably provides a more appropriate way of estimating the causal effect of foreign ownership on productivity. In the next Section we, therefore, turn to calculating the direct, indirect, total and marginal treatment productivity effects (defined in Section 3) by varying the proportion of treated firms in a cluster. ${ }^{16}$

\section{Treatment effects with interactions: main findings}

For ease of presentation, we plot the estimated effects along with their $95 \%$ confidence intervals. It is apparent from Figure 2 that the proportion of foreign-owned firms in a cluster matters significantly, both statistically and economically.

Our first finding is that the direct average treatment effects, i.e., the productivity premium due to having foreign ownership differs strongly as one varies the proportion of foreign firms in the cluster. While they are positive irrespective of the proportion of foreign firms in the cluster, it is apparent from Figure 2 that the share of foreign firms matters significantly for any conclusion one can draw from the data. This is in line with our

\footnotetext{
${ }^{16}$ We outline the main reasons why a simple linear model where the direct and indirect effects of FDI are estimated within a single framework is unlikely to be an adequate empirical tool in Appendix D.
} 
motivating discussion in Section 2, where we argue that foreign owned firms have higher investments in productivity enhancing activities and that such investments may be higher (in the presence of positive spillovers) the more prevalent are foreign firms in the cluster

We can see, for example, that the direct effect is smaller for a cluster with a 10 percent share of foreign owned firms than for a cluster with insignificant foreign presence. After the 10 percent mark we see strong increases in the direct effect with increasing proportions of foreign-owned firms. For example, the direct productivity effects of foreign ownership would be $20 \%$ and $35 \%$ when the proportions of foreign firms in the cluster are $20 \%$ and $50 \%$ respectively.

In contrast, we uncover significant negative indirect effects on non-treated (i.e. domestic owned) firms. In the context of the literature on FDI, we can interpret this as evidence for negative productivity spill overs. This is not unusual in the literature on spillovers, which in many cases finds negative effects of the presence of FDI on productivity of domestic firms (see Görg and Greenaway, 2004) and is generally regarded as indicating negative competition or market-stealing effects from multinationals. Interestingly, we document evidence that this effect varies with the proportion of foreign owned firms; it seems to be most negative around the $40 \%$ mark. This is a novel finding, as the literature generally only estimates a constant spillover effect that does not vary with the level of the proportion of foreign owned firms.

From the combination of direct and indirect effect we can calculate the total effect of the treatment. Note that, while these total effects on productivity are uniformly positive, they do not increase monotonically with the share of foreign owned firms. Rather, we find that the total effect declines when the proportion of foreign owned firms in a cluster moves from 0 to about 20. This is due to the negative indirect effects which outweigh the direct effects. Only after reaching this 20 percent threshold do we see further increases in the total effect with increasing shares of foreign firms in the cluster. Still, we find that even though we have 
strong evidence for negative spillovers (indirect effect), the total effect of the treatment (i.e., foreign ownership) is generally positive.

The non-monotonic relationship between the proportion of foreign firms in a cluster and the total treatment effect is further illustrated when one studies the marginal average treatment effects on the treated. Recall that this gives the marginal change in the potential outcome for treated firms when the proportion of treated firms changes from 0 to $p$. These marginal effects become increasingly negative up to a threshold of 20 percent. They only start turning positive after the $40 \%$ mark. Hence, this result indicates that low proportions of foreign ownership in a cluster are not optimal from the perspective of treated (i.e., foreign owned) firms. Instead, it seems to be the case that a "critical mass" of foreign owned firms in a cluster (with the critical mass point being in the region of $40 \%$ ) is necessary in order to stimulate productivity in foreign owned firms. This evidence thus suggests that foreign firms thrive in clusters with a high presence of other foreign firms. This is in line with arguments by Lee et al. (2013), Chen (2009) and Henderson (2003) who find that agglomerations of firms (in particular foreign owned) can be important for firm level productivity and development. Our evidence, however, shows that this is not necessarily a monotonically positive relationship, but that the positive effects only kick in after reaching a certain level of foreign presence in a cluster.

As our results thus far rely on labour productivity as outcome variable, we now provide a robustness check where we measure total factor productivity (TFP) using the Levinsohn and Petrin (2003) methodology. The results are presented in Figure 3. Note that the patterns of results look very similar to the patterns observed using labour productivity. The main difference is that the effects based on TFP have turning points at lower percentage shares of foreign firms. For example, we can see that the marginal treatment effects start to pick up at around 10 per cent of foreign owned firms in a cluster and become positive after 
reaching about 30 percent when using TFP. When using labour productivity, they only become positive after reaching around 40 percent of foreign owned firms in a cluster.

\section{Conclusions}

This paper offers a causal analysis of the direct and indirect effects of foreign ownership on firm level productivity of treated (i.e., foreign) and non-treated (i.e., domestic) firms. The approach we follow in this paper enables us to estimate, in a unified framework, the direct effect of foreign-ownership on the productivity of foreign firms, as well as two types of indirect effects, namely on domestic and foreign firms. These latter two effects provide estimates of "spillovers" from the presence of foreign-owned firms on foreign and domestic firms. Combining direct and indirect effects we can also calculate a total effect of foreign firms. Our approach thus allows us to distinguish between different types of treatment effects, which are not only academically interesting but also highly policy relevant.

Importantly, we provide empirical evidence that not only the direct effects vary systematically with the proportion of foreign firms in the cluster, but also the spillover effects differ strongly across such clusters. Specifically, the analysis shows that for our Chinese data spillovers on domestic firms become more negative with increasing presence of foreigninvested firms up to a threshold of around 40 percent foreign ownership in a cluster. After this threshold they become less negative.

For spillovers on other foreign firms we find that these are negative up to a threshold of 40 percent foreign ownership in a cluster. After this value they turn positive, however. This latter result provides an important finding for the academic literature and policy debate on the benefits from "agglomerations" of foreign owned firms, showing that these benefits are not uniform but depend strongly on the level of foreign ownership in a well-defined cluster. 
Combining our treatment effects we find a total effect that is positive but initially declines with low shares of foreign firms in a cluster. However, after reaching about 20 percent of foreign firms the total effect increases with increasing shares of foreign firms in the cluster. Hence, for policymakers, this might suggest that they might aim to encourage concentrations of foreign firms above these thresholds in a cluster.

Overall, our research suggests that estimating the various treatment effects described in this paper is a rewarding exercise as it sheds much needed light on the various mechanisms through which the proportion of foreign firms affects potential outcomes of foreign and nonforeign firms. In so doing, our paper provides important inputs into the policy debate on the benefits from inward foreign direct investment for host country firms. 


\section{References}

Aitken, Brian J., and Ann E. Harrison. (1999). `Do Domestic Firms Benefit from Foreign Direct Investment? Evidence from Venezuela', American Economic Review, 605-618.

Angelucci, M. and De Giorgi, G. (2009). 'Indirect Effects of an Aid Program: The Case of Progresa and Consumption', American Economic Review, 99, 486-508.

Arnold, J., Javorcik, B.S. (2009). 'Gifted kids or pushy parents? Foreign direct investment and plant productivity in Indonesia', Journal of International Economics 79 (1), 42-53.

Chen, Y. (2009). 'Agglomeration and location of foreign direct investment: The case of China', China Economic Review, 20, 549-557

$\mathrm{Du}, \mathrm{J}$ and Girma, S. (2009). 'The effects of foreign acquisitions on domestic and export markets dynamics in China', The World Economy 32, 164-177, 2009.

Ferracci, Marc, Jolivet, Grégory and van den Berg, Gerard (2014). 'Evidence of treatment spillovers within markets', Review of Economics and Statistics, forthcoming.

Fosfuri, A.; M. Motta and T. Rønde (2001), "Foreign Direct Investment and Spillovers Through Workers' Mobility”, Journal of International Economics, Vol. 53, pp. 205-222.

Fryges, H. and Wagner, J. (2008). 'Exports and Productivity Growth: First Evidence from a Continuous Treatment Approach', Review of World Economics, 144, 695-722.

Girma, S. and Görg, H. (2007a). 'Multinationals productivity advantage: Scale or technology?' Economic Inquiry, 45 (2) 350-362.

Girma, S. and Görg, H. (2007b). 'Evaluating the foreign ownership wage premium using a difference-in-differences matching approach', Journal of International Economics, 72, 97112.

Girma, S., Greenaway, D and Kneller, R. (2004). 'Does exporting increase productivity? A microeconometric analysis of matched firms', Review of International Economics, 12(5), 855-866.

Girma, S. and Wakelin. K. (2007). 'Local productivity spillovers from foreign direct investment in the U.K. electronics industry', Regional Science and Urban Economics, 37(3), $399-412$.

Görg, H. and Greenaway, D. (2004). 'Much ado about nothing? Do domestic firms really benefit from foreign direct investment?', World Bank Research Observer, 19, 171-197.

Görg, H. and Strobl, E (2005). 'Spillovers from Foreign Firms through Worker Mobility: An Empirical Investigation," Scandinavian Journal of Economics, 107, 693-709.

Guadalupe, M.; Kuzmina, Olga, and Thomas, C(2012). 'Innovation and Foreign Ownership,' American Economic Review, 102(7),3594-3627. 
Harris, R. and C. Robinson (2002). The effect of foreign acquisitions on total factor productivity: Plant-level evidence from UK manufacturing, Review of Economics and Statistics, 84, 562-568.

Haskel, Jonathan E., Sonia C. Pereira and Matthew J. Slaughter (2007). `Does Inward Foreign Direct Investment boost the Productivity of Domestic Firms?', Review of Economics and Statistics, 89 (3), 482-496.

Helpman, E., Melitz, M. and Yeaple, S. (2004). 'Exports versus FDI with Heterogeneous Firms', American Economic Review, 94, 300-316.

Henderson, J.V. (2003). 'Marshall's scale economies', Journal of Urban Economics 53, 1-28.

Heyman, F., Sjöholm, F. and Tingval, F. (2007). `Is there Really a Foreign Ownership Wage Premium? Evidence from Matched Employer-Employee Data', Journal of International Economics, 73 (2), 355-376.

Hirano, K. and Imbens, G.W. (2004). 'The propensity score with continuous treatments', in: Andrew Gelman and Xiao-Li Meng eds, Applied Bayesian Modeling and Causal Inference from Incomplete-Data Perspectives, Wiley.

Hirano, K., Imbens, G., and Ridder, G. (2003). `Efficient Estimation of Average Treatment Effects Using the Estimated Propensity Score', Econometrica, 71, 1161-1189.

Hudgens, M.G., and Halloran, M.E. (2008). 'Toward Causal Inference With Interference', Journal of the American Statistical Association, 103, 832-842.

Huttunen, K. (2007). 'The effect of foreign acquisition on employment and wages: Evidence from Finnish establishments', Review of Economics and Statistics, 89(3) 497-509.

Imai K. and van Dyk D.A. (2004). 'Causal inference with general treatment regimes: Generalizing the propensity score', Journal of the American Statistical Association 99, 854866.

Javorcik, B.S. (2004). 'Does Foreign Direct Investment Increase the Productivity of Domestic Firms? In Search of Spillovers through Backward Linkages', American Economic Review, 94, 605-627.

Keller, W. (2010), International Trade, Foreign Direct Investment, and Technology Spillovers, Chapter 19 in B. Hall, N. Rosenberg (eds.), Handbook of the Economics of Innovation, Elsevier North-Holland

Keller, W. and Yeaple, S. (2009). 'Multinational Enterprises, International Trade, and Productivity Growth: Firm-Level Evidence from the United States', Review of Economics and Statistics, 91 (4), 821-831.

Lee, Y., Yih-Luan Chyi, Eric S. Lin and Shih-Ying Wu (2013). 'Do local industrial agglomeration and foreign direct investment to China enhance the productivity of Taiwanese firms?', Journal of International Trade \& Economic Development, 22(6), 839-865. 
Levinsohn, J. and A. Petrin. 2003. "Estimating Production Functions Using Inputs to Control for Observables", Review of Economic Studies, 70(2), 317-341.

Manski, C. (1993), "Identification of Endogenous Social Effects: The Reflection Problem," Review of Economic Studies, 60(3), 531-542

Manski, C. (2013). 'Identification of treatment response with social interactions', The Econometrics Journal, 16(6), S1-S23.

Markusen, J.R. (2001), Multinational firms and the theory of international trade, MIT Press

Papke, .E. and Wooldrige, J. (1996). 'Econometric methods for fractional response variables with an application to 401(k) plan participation rates', Journal of Applied Econometrics, 11, 619-632.

Rosenbaum PR (2007). 'Interference between Units in Randomized Experiments', Journal of the American Statistical Association, 102, 191-200.

Rubin, D. B. (1974). 'Estimating Causal Effects of Treatments in Randomized and Nonrandomized Studies'," Journal of Educational Psychology, 66, 688-701.

Sobel M. (2006). 'What Do Randomized Studies of Housing Mobility Demonstrate? Causal Inference in the Face of Interference', Journal of the American Statistical Association, 101, 1398-1407.

Volpe Martincus, C. and Carballo, J. (2008). 'Is export promotion effective in developing countries? Firm-level evidence on the intensive and the extensive margins of exports', Journal of International Economics, 76(1), 89-106.

Wagner, J. (2002). 'The causal effects of exports on firm size and labor productivity: first evidence from a matching approach', Economics Letters, 77(2), 287-292.

$\mathrm{Xu}, \mathrm{X}$. and Y. Sheng (2012), 'Are FDI spillovers regional? Firm-level evidence from China', Journal of Asian Economics, 23, 244-258. 


\section{Figure 1}

Cluster-specific average treatment effects of FDI on productivity: with nonparametric regression on proportion of FDI in cluster

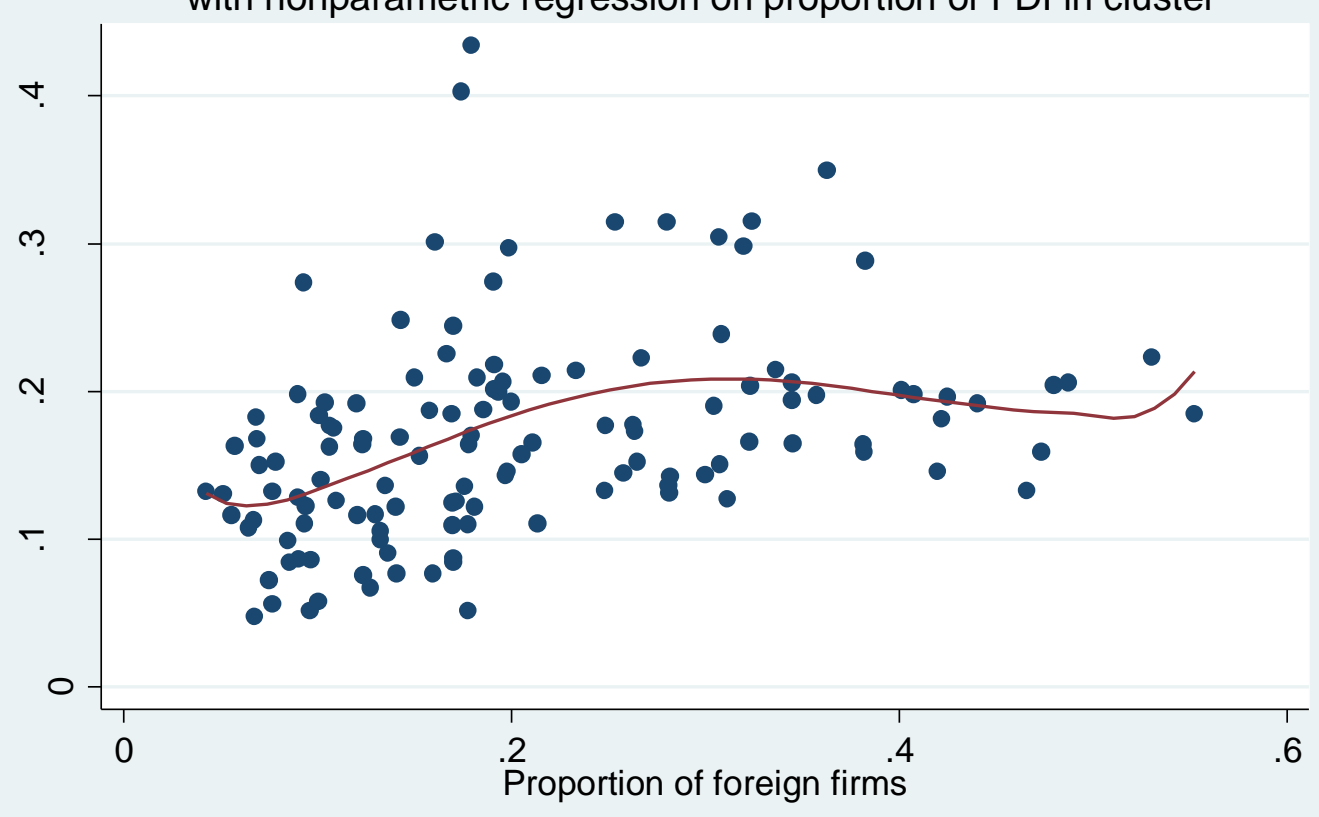
kernel $=$ epanechnikov, degree $=4$, bandwidth $=.17$

\section{Figure 2}

Treatment effects with externalities

Causal effects of FDI on productivity of foreign and domestic firms with $95 \%$ confidence intervals

\section{Direct causal effecis}

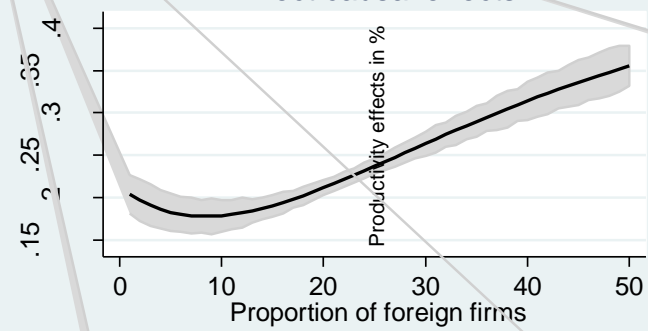

Total treatment effects

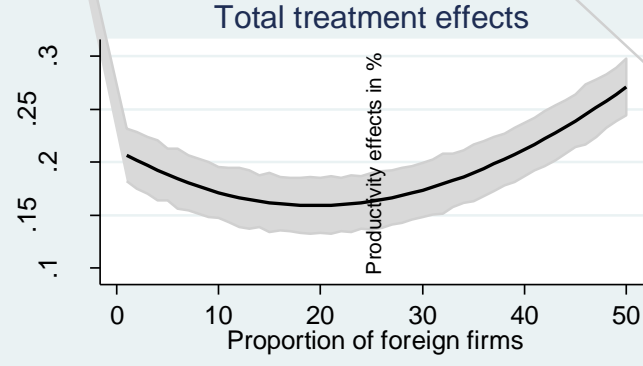

Indirect effects non-treated

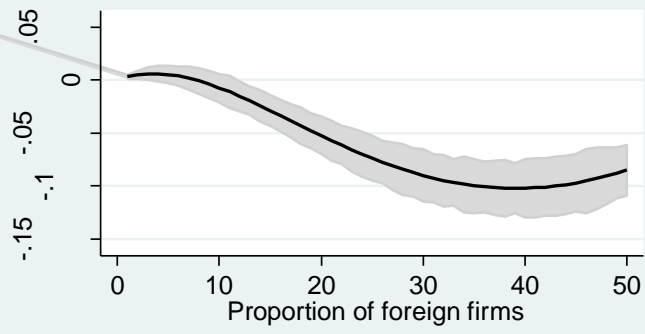

Marginal treatment effects on the treated

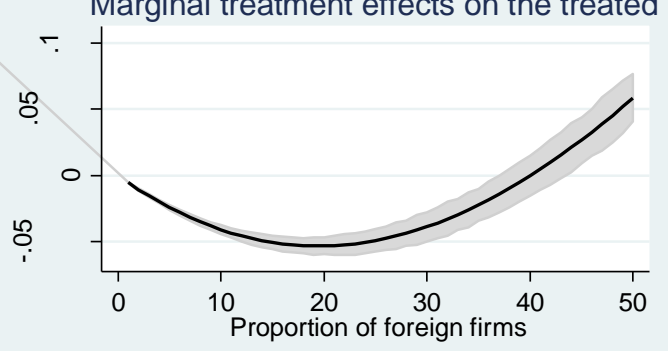

Confidence intervals based on bootstrapped standard errors

Note: productivity measured as labour productivity 


\section{Figure 3}

\section{Treatment effects with externalities}

Causal effects of FDI on TFP of foreign and domestic firms with $95 \%$ confidence intervals
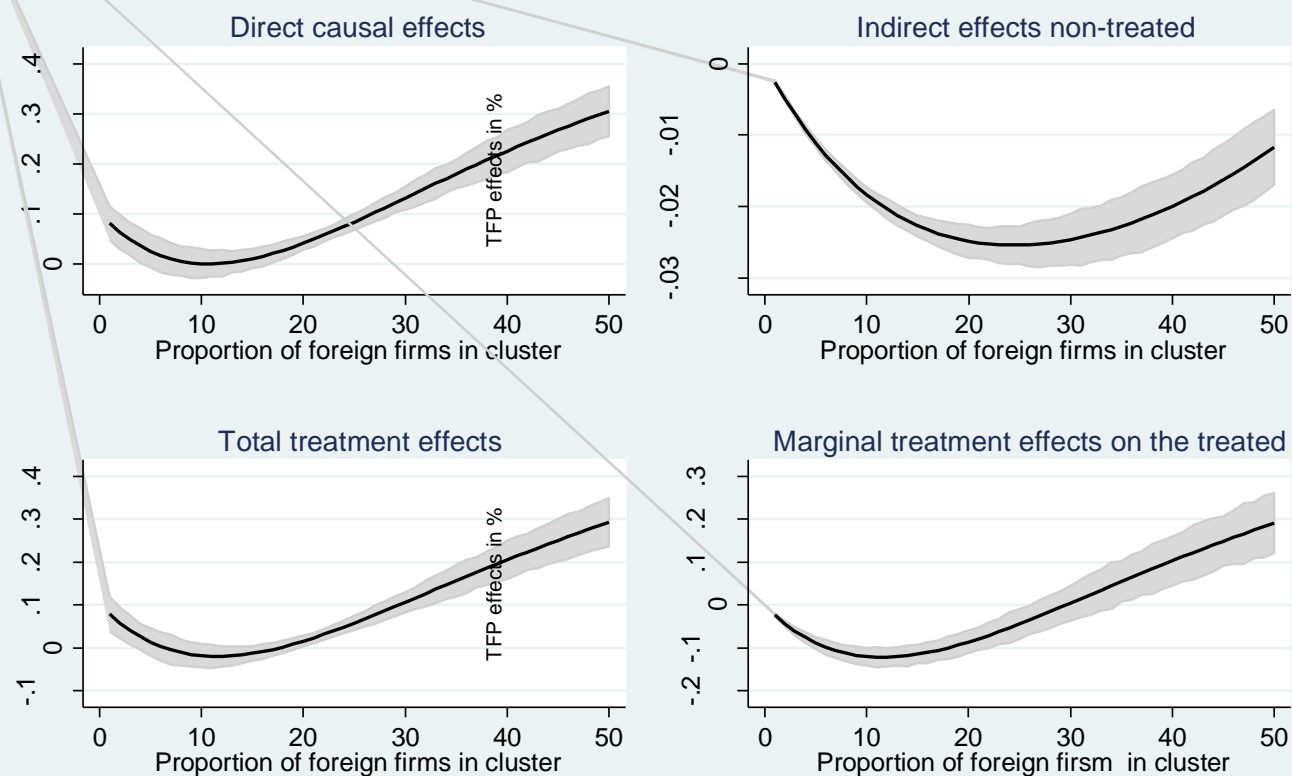

Confidence intervals based on bootstrapped standard errors

Note: productivity measured as total factor productivity 
Table 1

Summary statistics of some firm level variables of interest

\begin{tabular}{|l|c|c|c|c|}
\hline & Mean & $\begin{array}{c}\text { Standard } \\
\text { deviation }\end{array}$ & Min & Max \\
\hline Domestic firms & & & & \\
\hline Log productivity (2004) & 3.993 & 1.284 & -6.050 & 11.374 \\
\hline Log productivity (2006) & 4.149 & 1.080 & -4.901 & 9.600 \\
\hline Log wages (2004) & 2.418 & 0.505 & -3.135 & 8.440 \\
\hline Exporting intensity (2004) & 0.118 & 0.288 & 0.000 & 1.000 \\
\hline Size (log of assets, 2004) & 8.183 & 1.661 & -0.026 & 17.666 \\
\hline Log of age (2004) & 1.970 & 0.936 & 0.000 & 4.605 \\
\hline $\begin{array}{l}\text { Log of number of } \\
\text { foreign firms in region (2004) }\end{array}$ & 7.678 & 1.494 & 2.485 & 9.357 \\
\hline Number of firms & 133,010 & & & \\
\hline Foreign firms & & & & \\
\hline Log productivity (2004) & 4.055 & 1.345 & -4.723 & 11.613 \\
\hline Log productivity (2006) & 4.343 & 1.268 & -3.724 & 11.875 \\
\hline Log wages (2004) & 2.737 & 0.612 & -0.665 & 7.140 \\
\hline Exporting intensity 2004) & 0.452 & 0.438 & 0.000 & 1.000 \\
\hline Size (log of assets, 2004) & 8.939 & 1.724 & -0.026 & 16.685 \\
\hline Log of age (2004) & 1.842 & 0.727 & 0.000 & 4.554 \\
\hline $\begin{array}{l}\text { Log of number of } \\
\text { foreign firms in region (2004) }\end{array}$ & 8.360 & 1.073 & 2.485 & 9.357 \\
\hline Number of firms & 42085 & & & \\
\hline
\end{tabular}

Table 2

Summary statistics of some cluster level variables

\begin{tabular}{|l|c|c|c|c|c|}
\hline & Mean & $\begin{array}{c}\text { Standard } \\
\text { deviation }\end{array}$ & Min & Max & $\begin{array}{c}\text { Inter-quartile } \\
\text { range }\end{array}$ \\
\hline $\begin{array}{l}\text { Proportion of } \\
\text { FDI firms (2005) }\end{array}$ & 0.208 & 0.119 & 0.043 & 0.553 & 0.172 \\
\hline Average wage (thousand RMB) (2004) & 7.183 & 0.323 & 6.390 & 8.179 & 0.465 \\
\hline Average productivity (2004) & 4.269 & 0.372 & 3.380 & 5.418 & 0.470 \\
\hline Average export intensity (2004) & 0.235 & 0.127 & 0.029 & 0.610 & 0.168 \\
\hline Share of SOEs (2004) & 0.093 & 0.062 & 0.006 & 0.247 & 0.096 \\
\hline Average size (log of assets ,2004) & 8.520 & 0.439 & 7.788 & 10.041 & 0.450 \\
\hline Average age (2004) & 2.006 & 0.175 & 1.218 & 2.510 & 0.191 \\
\hline $\begin{array}{l}\text { Average log number } \\
\text { of FDI firms (2004) }\end{array}$ & 5.077 & 1.209 & 2.303 & 8.148 & 1.648 \\
\hline Number of clusters & 127 & & & & \\
\hline
\end{tabular}


Table 3

Number of foreign firms and proportion of foreign (treated) firms by cluster

\begin{tabular}{|c|c|c|c|c|c|c|c|c|c|c|c|}
\hline Cluster & $\mathrm{NF}$ & $\mathrm{PF}$ & Cluster & $\mathrm{NF}$ & $\mathrm{PF}$ & Cluster & NF & $\mathrm{PF}$ & Cluster & $\mathrm{NF}$ & $\mathrm{PF}$ \\
\hline 1 & 177 & 0.31 & 33 & 79 & 0.16 & 65 & 275 & 0.12 & 97 & 802 & 0.36 \\
\hline 2 & 211 & 0.49 & 34 & 132 & 0.28 & 66 & 526 & 0.18 & 98 & 73 & 0.12 \\
\hline 3 & 984 & 0.23 & 35 & 407 & 0.42 & 67 & 414 & 0.21 & 99 & 15 & 0.07 \\
\hline 4 & 247 & 0.2 & 36 & 302 & 0.19 & 68 & 603 & 0.38 & 100 & 37 & 0.04 \\
\hline 5 & 543 & 0.26 & 37 & 418 & 0.3 & 69 & 64 & 0.06 & 101 & 141 & 0.25 \\
\hline 6 & 458 & 0.35 & 38 & 630 & 0.21 & 70 & 19 & 0.07 & 102 & 442 & 0.4 \\
\hline 7 & 126 & 0.1 & 39 & 1180 & 0.48 & 71 & 40 & 0.07 & 103 & 297 & 0.12 \\
\hline 8 & 84 & 0.11 & 40 & 60 & 0.14 & 72 & 133 & 0.05 & 104 & 446 & 0.15 \\
\hline 9 & 74 & 0.1 & 41 & 21 & 0.14 & 73 & 90 & 0.1 & 105 & 558 & 0.17 \\
\hline 10 & 301 & 0.07 & 42 & 48 & 0.18 & 74 & 52 & 0.22 & 106 & 315 & 0.32 \\
\hline 11 & 122 & 0.08 & 43 & 67 & 0.07 & 75 & 54 & 0.27 & 107 & 65 & 0.08 \\
\hline 12 & 240 & 0.32 & 44 & 45 & 0.14 & 76 & 87 & 0.18 & 108 & 23 & 0.07 \\
\hline 13 & 776 & 0.44 & 45 & 43 & 0.18 & 77 & 90 & 0.26 & 109 & 125 & 0.31 \\
\hline 14 & 1065 & 0.28 & 46 & 62 & 0.34 & 78 & 77 & 0.18 & 110 & 290 & 0.47 \\
\hline 15 & 1689 & 0.26 & 47 & 103 & 0.11 & 79 & 99 & 0.3 & 111 & 132 & 0.09 \\
\hline 16 & 3234 & 0.31 & 48 & 218 & 0.15 & 80 & 36 & 0.17 & 112 & 299 & 0.2 \\
\hline 17 & 2592 & 0.55 & 49 & 138 & 0.13 & 81 & 31 & 0.14 & 113 & 229 & 0.2 \\
\hline 18 & 188 & 0.16 & 50 & 162 & 0.25 & 82 & 29 & 0.11 & 114 & 341 & 0.41 \\
\hline 19 & 25 & 0.16 & 51 & 10 & 0.09 & 83 & 87 & 0.11 & 115 & 34 & 0.09 \\
\hline 20 & 142 & 0.17 & 52 & 555 & 0.36 & 84 & 55 & 0.14 & 116 & 16 & 0.12 \\
\hline 21 & 212 & 0.1 & 53 & 898 & 0.47 & 85 & 94 & 0.19 & 117 & 145 & 0.32 \\
\hline 22 & 35 & 0.08 & 54 & 828 & 0.31 & 86 & 175 & 0.34 & 118 & 190 & 0.32 \\
\hline 23 & 137 & 0.2 & 55 & 1390 & 0.38 & 87 & 301 & 0.1 & 119 & 182 & 0.21 \\
\hline 24 & 321 & 0.38 & 56 & 1714 & 0.28 & 88 & 263 & 0.19 & 120 & 300 & 0.25 \\
\hline 25 & 385 & 0.18 & 57 & 3456 & 0.53 & 89 & 444 & 0.2 & 121 & 310 & 0.17 \\
\hline 26 & 288 & 0.19 & 58 & 73 & 0.13 & 90 & 412 & 0.26 & 122 & 268 & 0.43 \\
\hline 27 & 589 & 0.18 & 59 & 13 & 0.09 & 91 & 69 & 0.06 & 123 & 38 & 0.12 \\
\hline 28 & 954 & 0.34 & 60 & 99 & 0.17 & 92 & 120 & 0.17 & 124 & 43 & 0.17 \\
\hline 29 & 50 & 0.09 & 61 & 179 & 0.1 & 93 & 279 & 0.28 & 125 & 29 & 0.14 \\
\hline 30 & 64 & 0.13 & 62 & 75 & 0.13 & 94 & 188 & 0.17 & 126 & 87 & 0.09 \\
\hline 31 & 52 & 0.08 & 63 & 136 & 0.19 & 95 & 294 & 0.17 & 127 & 70 & 0.09 \\
\hline 32 & 133 & 0.06 & 64 & 348 & 0.42 & 96 & 362 & 0.18 & & & \\
\hline
\end{tabular}

Note: Cluster $=$ Cluster (region-sector) number; $\mathrm{NF}=$ Number of foreign firms ; $\mathrm{PF}=$ Proportion of foreign (treated firms) 
Table 4

\section{Correlation matrix of cluster level variables}

\begin{tabular}{|l|c|c|c|c|c|c|c|c|}
\hline & $\begin{array}{l}\text { Proportion } \\
\text { of FDI firm }\end{array}$ & $\begin{array}{c}\text { Average } \\
\text { wage }\end{array}$ & $\begin{array}{c}\text { Average } \\
\text { productivity }\end{array}$ & $\begin{array}{c}\text { Average } \\
\text { export } \\
\text { intensity }\end{array}$ & $\begin{array}{c}\text { Average } \\
\text { export } \\
\text { intensity }\end{array}$ & $\begin{array}{c}\text { Average } \\
\text { size }\end{array}$ & $\begin{array}{c}\text { Average } \\
\text { age }\end{array}$ & $\begin{array}{c}\text { Log } \\
\text { number } \\
\text { FDI } \\
\text { firms }\end{array}$ \\
\hline $\begin{array}{l}\text { Proportion of } \\
\text { FDI firms }\end{array}$ & 1 & & & & & & & \\
\hline Average wage & $0.503^{* * *}$ & 1 & & & & & & \\
\hline $\begin{array}{l}\text { Average } \\
\text { productivity }\end{array}$ & $0.222^{*}$ & $-0.186^{*}$ & 1 & & & & & \\
\hline $\begin{array}{l}\text { Average export } \\
\text { intensity }\end{array}$ & $0.657^{* * *}$ & $0.425^{* * * *}$ & -0.145 & 1 & & & & \\
\hline Share of SOEs & $-0.415^{* * *}$ & 0.0968 & -0.172 & $-0.529^{* * *}$ & 1 & & & \\
\hline Average size & $-0.175^{* *}$ & $0.341^{* * * *}$ & 0.0395 & $-0.348^{* * *}$ & $0.402^{* * *}$ & 1 & & \\
\hline Average age & -0.0969 & $0.404^{* * * *}$ & $-0.223^{* *}$ & $-0.258^{* * *}$ & $0.606^{* * *}$ & $0.486^{* * *}$ & 1 & \\
\hline $\begin{array}{l}\text { Log number } \\
\text { of FDI firms }\end{array}$ & $0.654^{* * * *}$ & 0.147 & 0.0871 & $0.736^{* * *}$ & $-0.642^{* * *}$ & - & - & 1 \\
\hline
\end{tabular}

Notes: ${ }^{*} p<0.05,{ }^{* *} p<0.01,{ }^{* * *} p<0.001$ 


\section{Appendix A}

Geographic classification used in this paper

\begin{tabular}{|c|l|c|}
\hline AREA & \multicolumn{1}{|c|}{ PROVINCES } & $\begin{array}{c}\text { Share of } \\
\text { foreign ownership }\end{array}$ \\
\hline 1 & Beijing and Tianjin & 0.25 \\
\hline 2 & Shanghai & 0.39 \\
\hline 3 & Liaoning and Shandong & 0.21 \\
\hline 4 & Jiangsu & 0.24 \\
\hline 5 & Fujian and Zhejiang & 0.23 \\
\hline 6 & Guangdong and Hainan & 0.44 \\
\hline 7 & Inner Mongolia, Hebei and Shanxi & 0.10 \\
\hline 8 & Jilin, Heilongjiang & 0.12 \\
\hline 9 & Jiangxi, Anhui & 0.12 \\
\hline 10 & Qinghai, Henan, Gansu, Shaanxi, Hunan, & 0.08 \\
\hline 11 & Ningxia, Hubei, Guangxi and Xinjiang & 0.09 \\
\hline & Guizhou, Yunnan, Sichuan and Chongqing & \\
\hline
\end{tabular}

Industrial classification used in this paper

\begin{tabular}{|c|c|c|}
\hline $\begin{array}{r}\text { Industry } \\
\text { group }\end{array}$ & Industry name & $\begin{array}{c}\text { Share of } \\
\text { foreign ownership }\end{array}$ \\
\hline 1 & Food processing & 0.16 \\
\hline 1 & Food production & 0.25 \\
\hline 1 & Beverages & 0.18 \\
\hline 2 & Textiles & 0.23 \\
\hline 2 & Garments and other fibre products & 0.44 \\
\hline 2 & Leather, furs, down related products & 0.42 \\
\hline 3 & Timber processing & 0.20 \\
\hline 3 & Furniture manufacturing & 0.35 \\
\hline 3 & Papermaking and paper products & 0.17 \\
\hline 3 & Printing and record medium reproduction & 0.14 \\
\hline 4 & Rubber products & 0.26 \\
\hline 4 & Plastic products & 0.29 \\
\hline 5 & Smelting and pressing of ferrous metals & 0.11 \\
\hline 5 & Smelting and pressing of nonferrous metals & 0.16 \\
\hline 6 & Electric equipment and machinery & 0.25 \\
\hline 6 & Electronic and telecommunications & 0.54 \\
\hline 6 & Instruments and meters & 0.36 \\
\hline 6 & Other electronic equipment & 0.38 \\
\hline 7 & Raw chemical materials and chemical products & 0.17 \\
\hline 8 & Medical and pharmaceutical products & 0.19 \\
\hline 9 & Non-metal mineral products & 0.17 \\
\hline 10 & Metal products & 0.22 \\
\hline 11 & Ordinary machinery & 0.18 \\
\hline 12 & Special purpose equipment & 0.24 \\
\hline 13 & Transport equipment & 0.19 \\
\hline
\end{tabular}




\section{Appendix B}

\section{Summary statistics of estimated coefficients from the first stage cluster-specific}

\section{Logit model ( $\mathrm{N}=127)$ :}

\begin{tabular}{|c|c|c|c|c|c|c|}
\hline $\begin{array}{l}\text { Pre-treatment } \\
\text { covariates } \\
\text { (in 2004) }\end{array}$ & Mean & $\begin{array}{l}\text { Average } \\
\text { St. error }\end{array}$ & Min & Max & $\begin{array}{l}\text { Proportion } \\
\text { of clusters } \\
\text { with } \\
\text { significant } \\
\text { coefficients }\end{array}$ & $\begin{array}{c}\text { Proportion } \\
\text { of clusters } \\
\text { with } \\
\text { balanced } \\
\text { covariates }\end{array}$ \\
\hline $\begin{array}{l}\text { Log } \\
\text { productivity }\end{array}$ & .0890319 & .1203289 & -.2622438 & .597029 & .2755906 & 0.976 \\
\hline Log wages & 1.187789 & .2782815 & -1.787512 & 2.724028 & .8976378 & 0.984 \\
\hline Wages growth & -.5439145 & .3858767 & -8.982675 & .4646787 & .488189 & 0.992 \\
\hline $\begin{array}{l}\text { Productivity } \\
\text { growth }\end{array}$ & -.0824834 & .1951044 & -1.312997 & 2.76314 & .2519685 & 0.984 \\
\hline $\begin{array}{l}\text { Exporting } \\
\text { intensity }\end{array}$ & 2.701552 & .576253 & -3.520742 & 11.78326 & .9606299 & 0.961 \\
\hline Size & .295387 & .0829834 & -.1505758 & .6941422 & .7874016 & 0.976 \\
\hline Age & -.3614924 & .1539911 & -.9862373 & .1851604 & .6692913 & 0.976 \\
\hline $\begin{array}{l}\text { Log of number } \\
\text { of foreign firms } \\
\text { in region }\end{array}$ & .4355861 & 1.043163 & -10.30238 & 23.77369 & .6141732 & 0.835 \\
\hline
\end{tabular}

1. Estimated coefficients from binary logit models can be interpreted as the effects of the covariates on the log odd-ratio of foreign ownership.

2. The penultimate column gives the proportion of individually statistically significant coefficients at $10 \%$ level or lower. In all cases the coefficients are jointly statistically significant.

3. The last column gives the results from the covariate balancing test which consists of testing (at $10 \%$ level or lower) for difference in the means of the covariates in treatment and control groups, conditional on the estimated propensity score. 


\section{Appendix C: Calculating treatment effects}

We investigate the existence of causal links between potential outcomes and the proportion of treated firms in a cluster. For this purpose, we treat the cluster level average potential outcomes $\bar{y}_{r}^{1}$ and $\bar{y}_{r}^{0}$ as the "outcome" variables and the corresponding proportion of foreign-owned firms, $p_{r}$, as the "treatment" variable.

Since we now have a continuous treatment variable rather than a binary one, we employ the causal inference approach for continuous treatments (Hirano and Imbens, 2004; Imai and van Dyk, 2004). ${ }^{17}$ A key result from this literature is that causal inference can be conducted by conditioning on the generalised propensity score (GPS), which is the conditional density of the treatment given some pre-treatment variables. Hence, this can be seen as an extension of the conditional independence assumption (CIA) to the case of a continuous treatment variable. Since our assumption is that of "no interaction across clusters", SUTVA holds for the cluster level analysis.

Since the treatment variable is a proportion between 0 and 1, we estimate the determinants of treatment using the fractional logit model due to Papke and Wooldridge (1996). In the empirical implementation, we condition $p_{r}$ on a vector $\boldsymbol{Z}$ of observable pre-treatment cluster characteristics which include average wages, productivity, size, age and the proportion of exporting, state-owned and the number of foreign owned firms in the region.. The econometric estimates and corresponding marginal effects from this fractional logit model, and balancing test results are reported in Tables $\mathrm{C} 1$ and $\mathrm{C} 2$.

Letting $\hat{\lambda}$ be the vector of estimated coefficients from the fractional logit model, the GPS conditional on $\boldsymbol{Z}$ and $\mathrm{p}_{\mathrm{r}}$ can then be obtained as

$$
\hat{G}_{r}=\left[\frac{e^{Z_{i} \hat{\lambda}}}{1+e^{Z_{i} \hat{\lambda}}}\right]^{p_{r}}\left[1-\frac{e^{Z_{i} \hat{\lambda}}}{1+e^{Z_{i} \hat{\lambda}}}\right]^{1-p_{r}}
$$

\footnotetext{
${ }^{17}$ See Du and Girma (2009), and Fryges and Wagner (2008) for international trade applications of GPS matching techniques.
} 
We then estimate the expected values of each of the two potential outcomes $\left(\bar{y}_{r}^{1}\right.$ and $\left.\bar{y}_{r}^{0}\right)$ at cluster level conditional on $\hat{G}_{r}$ and $p_{r}$. These expected values are unknown and can be estimated using a polynomial approximation (Hirano and Imbens, 2004) such as the following quadratic form which is often found to be adequate: ${ }^{18}$

$$
E\left[y_{r}^{d} \mid \hat{G}_{r}, p_{r}\right]=\beta_{0}+\beta_{1} \hat{G}_{r}+\beta_{2} p_{r}+\beta_{3} \hat{G}_{r}^{2}+\beta_{4} p_{r}^{2}+\beta_{5} \hat{G}_{r} p_{r}
$$

with sample counterpart

$$
\frac{1}{R} \sum_{r=1}^{127} \hat{\beta}_{0}+\hat{\beta}_{1} \hat{G}_{r}+\hat{\beta}_{2} p_{r}+\hat{\beta}_{3} \hat{G}_{r}^{2}+\hat{\beta}_{4} p_{r}^{2}+\hat{\beta}_{5} \hat{G}_{r} p_{r}
$$

In Figure C1, we plot the 95\% confidence regions of the two potential outcomes $\bar{y}_{r}^{1}$ and $\bar{y}_{r}^{0}$ against $p_{r}$ (based on bootstrapped standard errors) over the practically feasible range of 0 to $50 \%^{19}$. This clearly shows that the potential outcomes for productivity (for treated and untreated firms) vary systematically with the treatment level in the cluster. Given our econometric approach, we can interpret this as a causal relationship, i.e., changes in the treatment level per cluster lead to changes in potential outcomes. This indicates that SUTVA does not hold in our analysis.

The thus calculated potential outcomes for different levels of $p_{r}$ are then used to calculate the treatment effects described in equations (11) to (14).

\section{Calculating standard errors}

To illustrate how the bootstrapped standard errors are calculated, we take the example of estimating the indirect effects of FDI using the formula given in Equation (12 3 ). This estimator is defined as the change in the potential outcome of non-foreign-owned firms resulting from increasing the cluster-specific proportion of foreign firms from 0 to $p \in\{0,1\}$

\footnotetext{
${ }^{18}$ Note that the parameters of such parametric approximation do not have any behavioural interpretation (Hirano and Imbens, 2004). These are used to obtain an unbiased estimator of the population mean.

${ }^{19}$ In our data, the proportion of foreign owned firms is less than $50 \%$ in $98 \%$ of the clusters.
} 


$$
\bar{\gamma}_{p 0}^{00}=\bar{y}_{p}^{0}-\bar{y}_{0}^{0}
$$

The average treatment effect based on our 127 clusters (indexed by c below) is naturally estimated as

$$
\bar{\gamma}_{\mathrm{p} 0}^{00}=\frac{1}{127} \sum_{\mathrm{c}=1}^{127} \mathrm{y}_{\mathrm{pr}}^{0}-\mathrm{y}_{0 \mathrm{r}}^{0}
$$

Recall that the ys in the above equation are potential outcomes -based on the inverse probability-weighted regression (Equation 15). The issue here is that standard formula for calculation the standard errors of means will be inadequate due the need of accounting for the fact the propensity score are estimated. Accordingly we compute bootstrapped standard errors via resampling with replacement. In our practical estimation we implemented 200 bootstraps (indexed by B below) and used the following formula:

$$
\text { s. } e\left(\bar{\gamma}_{\mathrm{p} 0}^{00}\right)=\sqrt{\frac{1}{200} \sum_{\mathrm{B}=1}^{200}\left(\bar{\gamma}_{\mathrm{p} 0, \mathrm{~B}}^{00}-\bar{\gamma}_{\mathrm{B}}^{00}\right)^{2}}
$$

with $\bar{\gamma}_{\mathrm{B}}^{00}=\frac{1}{200} \sum_{\mathrm{B}=1}^{200} \bar{\gamma}_{\mathrm{p} 0, \mathrm{~B}}^{00}$ 


\section{Figure C1}

Average potential productivity change with and without FDI Point estimates and $95 \%$ confidence intervals

Firms without FDI

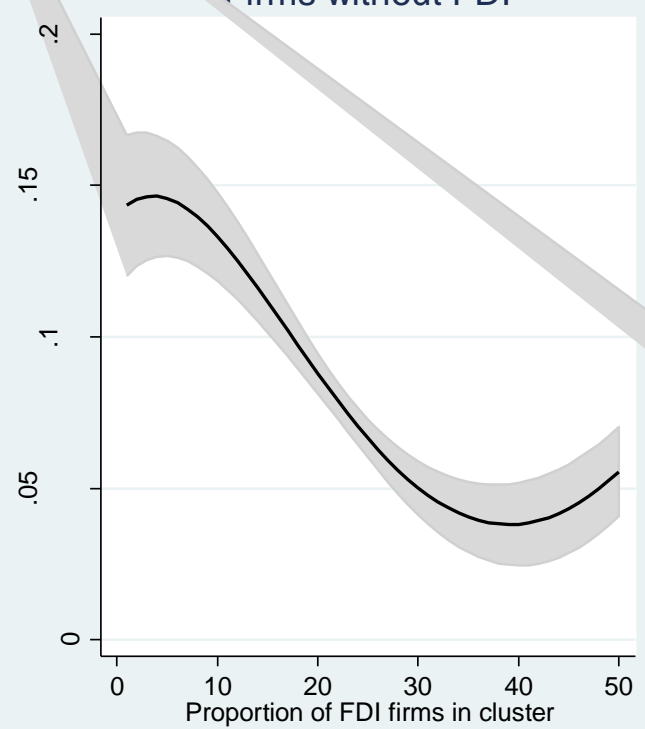

Firms with FDI

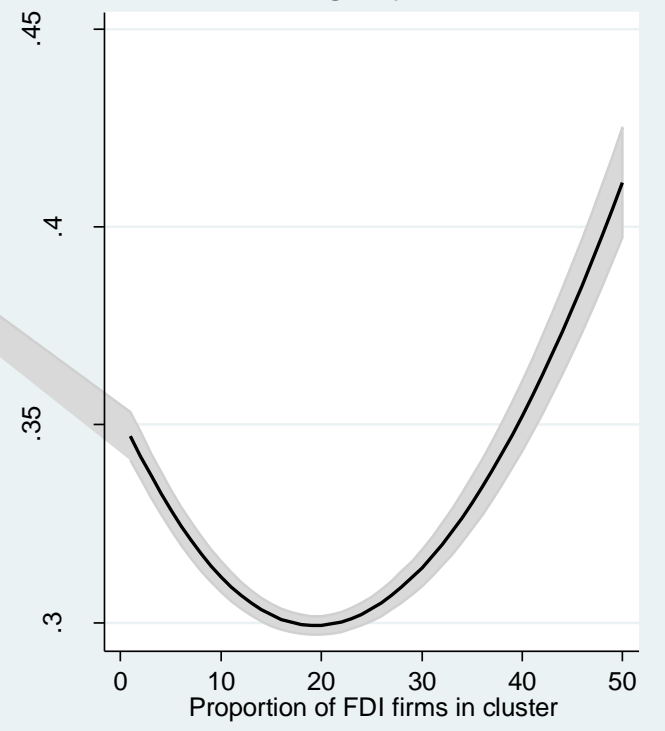

Confidence intervals based on bootstrapped standard errors 
Table C1: Estimated coefficients and marginal effects from the fractional logit model:

Dependent variable: proportion of FDI firms in cluster

Notes:

\begin{tabular}{|l|l|l|}
\hline & $\begin{array}{c}\text { Estimated } \\
\text { coefficients }\end{array}$ & $\begin{array}{c}\text { Marginal } \\
\text { effects }\end{array}$ \\
\hline Wages & $1.024^{* * *}$ & $0.158^{* * *}$ \\
\hline Productivity & $(0.1660)$ & $(0.0258)$ \\
\hline & $0.695^{* * *}$ & $0.107 * * *$ \\
\hline Export intensity & $(0.1155)$ & $(0.0181)$ \\
\hline & $0.985^{*}$ & $0.152^{*}$ \\
\hline SOE share & $(0.5659)$ & $(0.0871)$ \\
\hline & -1.200 & -0.186 \\
\hline Log of number of FDI Firms & $(0.9849)$ & $(0.1523)$ \\
\hline & $0.218^{* * *}$ & $0.034 * * *$ \\
\hline Size & $(0.0496)$ & $(0.0077)$ \\
\hline & $-0.242 * *$ & $-0.037 * *$ \\
\hline Age & $(0.0997)$ & $(0.0155)$ \\
\hline & 0.414 & 0.064 \\
\hline Observations & $(0.2888)$ & $(0.0448)$ \\
\hline & 127 & \\
\hline
\end{tabular}

(i) Standard errors are given in parenthesis

(ii) $\quad * p<0.10, * * p<0.05, * * * p<0.01$

Table C2: Balancing tests second stage estimation

\begin{tabular}{|l|r|r|r|}
\hline $\begin{array}{c}\text { Covariate } \\
\text { (pre-treatment period) }\end{array}$ & Quartile 2 & Quartile 3 & Quartile 4 \\
\hline Wages & 0.30 & 0.16 & 0.37 \\
\hline Productivity & 0.29 & 0.70 & 0.42 \\
\hline Export intensity & 0.44 & 0.75 & 0.92 \\
\hline SOE share & 0.72 & 0.52 & 0.93 \\
\hline Number of FDI firms & 0.14 & 0.05 & 0.08 \\
\hline Size & 0.55 & 0.68 & 0.89 \\
\hline Age & 0.28 & 0.45 & 0.45 \\
\hline
\end{tabular}

Note: Since the treatment is continuous we divided the observations into four groups by treatment quartiles and conditional on the generalised propensity score, we tested for equality of means of each of the covariates across all quartiles (using Quartile 1 as the base group). We did not reject the null hypothesis of equality of means in any of the tests whose p-value are reported below. 


\section{Appendix D}

Following the very helpful suggestion of a referee, we outline the main reasons why a simple linear model where the direct and indirect effects of FDI are estimated within a single framework is unlikely to be an adequate empirical tool.

Suppose we aim to estimate the direct and indirect effects of FDI on an outcome variable $y$ :

$$
y_{i r}=\alpha+\sum_{r=1}^{R} \beta_{r} d_{i r}+\gamma p_{r}+\delta p_{r} * d_{i r}+\varepsilon_{i r}
$$

In the above equation $r=1 \ldots \mathrm{R}$ indexes clusters and $\mathrm{i}=1 \ldots \mathrm{N}$ denotes firms within clusters, where for simplicity we assume each cluster has the same number of firms $\mathrm{N}$.

We define $d=1$ if the firm is foreign owned, and 0 else. Thus the $\beta$ 's would capture clusterspecific direct effects of FDI. $p_{r}=\frac{1}{N} \sum_{i=1}^{N} d_{i r}$ is the average foreign presence in cluster $\mathrm{r}$. Thus $\gamma$ would measure FDI spillovers to domestic firms, whereas $\gamma+\delta$ would identify FDI spillovers to foreign firms.

The estimation of this simple yet attractive empirical model is fraught with difficulties, however. Firstly, since there is selection at both firm and cluster level (as argued in the main body of this paper), identification would involve estimating two (generalised) propensity scores, one at firm level (say $P 1_{i}$ ) and one at cluster level (say $P 2_{i}$ ). However, to the best our knowledge, there is no available estimator which can deal, within a single equation, with two propensity-scores estimated at two different levels. So it would not suffice to estimate equation [D1] by inverse probability weighted regression, with treated firms getting weight of $1 / \mathrm{p} 1$ and non-treated firms getting weight of $1 / 1-\mathrm{p} 1$, as we would still have $E\left(\varepsilon_{\text {ir }} \mid p_{r}\right) \neq 0$ rendering the resulting estimator inconsistent.

The above problem notwithstanding, the second issue associated with estimating equation [D1] has to do with the fact that it does not, unlike the estimation approach advocated in this paper, allow for a richer counterfactual analysis. For example the relationship between y and $p_{r}$ is essentially linear restricting spillovers to be a monotonic function of foreign presence. 
The third problem with the estimation of equation [D1], especially the inclusion of the term capturing FDI spillovers to foreign firms, is a variant of the well-known reflection problem in social interaction models (see Manski, 1993). To be more precise, foreign firm i contributes $1 / \mathrm{N}$ to $p_{r}$ (the FDI variable). Consequently it is conceptually difficult to isolate direct from indirect effects in this setup, again the problem of dealing with two propensity scores estimated at two different levels notwithstanding. 